\title{
组建教师成长共同体 引领互动共享新发展
}

徐卫庆

浙江省杭州市萧山区万向初级中学

DOI:10.32629/er.v3i6.2836

[摘 要] 品味平凡的教师生活, 教师享受着精神生活的自我满足感, 品尝着教师职业生活的自我幸福感。教师的成长离不开教师群体, 教师的一 路成长需要有智慧的引路人、温暖的同行者,需要有一个共同发展成长的共同体。

[关键词] 教师成长; 共同体; 引领; 互动共享

\section{1 教师成长共同体的组建定位}

1. 1 教师成长共同体组建

1. 1. 1 组建校级层面的教师成长共同体

学校要加强教师队伍建设, 组建运行教师成长共同体, 在传统学科教 研组基础上组建成长共同体, 或在大学科层面组建成长共同体, 或在相应 教师层面组建成长共同体。

组建的共同体应有 “和谐团结、合力发展” 的共同理念, 把团队建设 成 “学习、工作、发展的共同体”, 形成 “和谐发展、合力发展、风格化 发展” 的鲜明特色。

和谐发展, 教师之间关系和谐, 共同体为每位教师的发展创设了良好 的氛围。团结、和谐、人际关系融洽, 共同体内教师在同事之外还有一种 兄弟姐妹的情谊, 家一样的和谐的感觉, 使每个人都产生强烈的归属感, 大 家共同学习、认真工作、和谐发展。

合力发展, 依靠每个教师、提高每个教师, 让每个教师都得到发展是共 同体的宗旨和追求, “一花独放不是春, 万紫千红春满园”。共同体内教师 以互动促成长, 教师间多引导、压担子、给机会, 努力促进青年教师的快速 成长、骨干教师的全面成长、名优教师的优质发展。

风格化发展, 在形成合力的基础上, 共同体鼓励教师追求教学艺术, 形 成自己的教学风格。青年教师要向名优教师学习, 但学习不能成为不走样 的拷贝, 而是在学习师傅长处的同时, 根据自己的个性特色结合教学实际, 努力形成自己的教学风格。

1. 1. 2组建区域层面的名师成长共同体

区域层面的名教师培养, 可以采用组建运行校际名优教师成长共同 体, 或教育行政区域内名师成长共同体 (或名师工作室) 名师成长共同体, 立足共同体实际, 务实工作, 力求创新, 努力促进共同体全体成员在业务 素养、道德修养等方面有较大幅度的提高, 以促进共同体全体成员的专业 成长, 培养更多名师为工作目标。名师成长共同体紧紧围绕促进共同体成 员专业成长的主题, 按照 “有分有合” 的原则, 在遵循共同体统一计划和共 同参与的前提下, 主要依托学科教研工作, 并与之整合开展研修活动。

重点开展做好三方面工作: 第一, 通过理论学习和研讨交流, 进一步转 变教育理念, 提高自身理论素养。第二, 通过开课、观课和磨课, 进一步提 高课堂教学水平。第三, 通过课题研究和论文等的撰写与交流, 进一步提高 教育教学研究水平。

名师成长共同体, 这不是一个组织机构, 而是一个有共同的价值理念 的教师而相聚在一起的家园。

\section{2 教师成长共同体的定位}

组建运行教师成长共同体, 通过导师专业引领、同伴互动共享、自我 规划反思, 提升共同体内每一成员的教学与研究能力, 更好促进学生生命 成长。
1.2. 改进教学行为, 使教师的课堂教学焕发出生命活力

共同体成员间的相互学习交流实践, 使教师树立了新的教学观, 提升 教学理念, 提升教学内容的处理能力和课堂教学的驾驭能力, 并在实践中 有效运用。

教育的使命是促进学生的生命成长、教会学生追求幸福。在教学中教 师要积极乐观的情绪教学感染教育学生, 把教学变成一项有生命力的情感 活动, 让学生体验到生命成长的乐趣, 使学生在幸福快乐中成长。

1.2.2提升研究能力, 让教师的教育研究成为自觉的行为

共同体成员间的相互学习交流实践, 教师要以研究者的心态置身于教 学情境中, 以研究者的目光审视已有的教学实际问题, 使教师的科研意识、 研究能力不断增强, 对已有的工作更愿意思考, 对于新的问题也更敏感, 更 有创见。

教育科研使教师发现新的更丰富的自我, 使教师启动新的更广阔的教 学天地。

\section{2 教师成长共同体的策略探究}

2. 1 导师引领一一引导专业成长发展

名师成长共同体 (名师工作室), 配备名师为导师, 他们有较系统的教 育理论修养, 有较宽厚的教育实践功底, 有较广阔的教育观察视野。他们 “站得高、钻得深、看得远”, 拥有很新的理念和经验, 从整体上把握课堂 教学, 对教师的专业引领居高临下, 使教师有大开眼界、耳目一新之感, 同 时, 又为教师提供将新理念转化为可操作的实践。导师引领主要有专题学 术报告、理论学习辅导讲座与座谈、教学现场指导等具体形式, 从理论高 度和教育实践中引领教师登上发展的快船。

2.1. 1 从理论高度引领

导师具有较高的理论素养, 见多识广, 能用理论去关照实践中的问题, 帮助教师从理论的高度去发现问题、分析问题、认识问题, 从而揭示问题 的实质。尤其是导师结合具体教学现象阐述理论、运用理论, 使理论具体 化、直观化, 使教师易于理解和把握。

2.1.2 从教育实践中引领

导师指导教育教学工作时, 常常把前沿的最新信息、独到的见解、鲜 明的观点、最具实效的做法呈现在教师面前, 引领教师快速成长。导师具 有较强的观察、分析和概括能力, 具有对话技巧。导师在实践中对教师引 领, 善于从教师习以为常、熟视无睹的教育现象中发现问题, 这种 “发现” 往往使教师 “大吃一惊” 或产生 “原来如此” 的感叹。导师从看似成堆的 问题中, 抓住核心问题, 帮助教师“拨开云雾见太阳”, 使教师产生害然开 朗、茅塞顿开之感。
2. 2 联动研究一一同伴互动才智升级
2.2.1 “专题问题” 联动研究
以学校发生的、教师亲历的真实问题为中心 (问题强调自下而上), 以 
校级教师成长共同体为单位, 结合自己学科实际组织讨论、交流, 找出自己 学科存在的问题和薄弱环节, 转化为课题研究专题, 并以学生发展为本, 深 入反思, 对学科教学观念、教学策略和教学实践进一步的分析, 及时调整教 学行为。

以 “发现问题、组织专题、研究问题” 的策略, 理论学习与教学实 践的多层次结合, 具体的模式: 发现问题, 确立主题----专题学习, 提高 认识-----案例分析, 研究实践----集体评议, 反思调整----归纳共识, 生成问题。

在专题内容的研讨中, 共同体教师间相互支持, 交流分享, 每个教师 在贡献自己智慧的同时, 又有了新的收获, 每个人都经历了帮助别人和 得到帮助的过程, 获得共同提高; 共同体发挥成员集体智慧, 得出研究成 果 (或叙事研究报告、教学案例、研究论文、心得感悟等), 进行探讨、 改进、推广。

\subsection{2 “课堂教学” 联动研究}

目前, 许多活动形式限于一般的听课评课, 或者考试交流, 活动形式比 较单一。对活动成效的反馈和小结工作做得较少, 还有活动安排的系统性、 连续性也不够。因此, 学科教研共同体可以安排以课堂教学主题的系列联 动研究。

基本模式为:

课堂展示 $\rightarrow$ 互动互评 $\rightarrow$ 专家引领 $\rightarrow$ 课堂展示完善与创新 $\rightarrow$ 集体互动 与反思 $\rightarrow$ 精品展示

课堂展示: 学科教研成长共同体确定教学内容, 并确定教师上课;

互动点评: 全体听课教师对该教师本节课的课堂教学进行互动点评;

专家引领: 每次活动邀请教研员或学科带头人组成专家组, 结合听 课互动点评的情况对本节课做专业性点评, 重点解决课堂中存在的问题 与困惑;

课堂展示完善与创新: 该教师吸收教师的互动点评与专家组的意见后 精心备课后, 仍由该教师上同一节内容;

集体互动与反思: 听课教师对该教师在解决前一堂课中的不足, 与本 堂课的亮点作点评与交流, 并对两堂课进行对比分析, 得出结论。

精品展示: 由共同体选派参与活动全过程的、课堂教学水平颇高的教 师根据前五步的交流与反思, 展示同一节内容。

\section{3 资源共享——合作共享教学资源}

\section{1 师资合作共享}

教师成长共同体, 进行同伴间合作互助, 师资互补共享。

智者引领, 示范教学。各学科都有一些市区级优秀教师、教坛新秀、 学科带头人。通过这些骨干教师说课、讲解教学设计意图、示范教学, 在 课堂教学中表露新课程理念, 让教师从课堂教学中较为具体地、直观地看 到新课程的教学理念, 使新的教学理念、新的教法、学法更鲜活地展现在 其他教师面前, 让教师的教学行为有着策略上的启发。发挥优质教学资源 的作用, 激活群体智慧。

师徒结对, 共营发展。学校可采用共同体内与单项强势教师牵手的策 略, 如, 有的教师擅长科研; 有的教师擅长课堂教学; 有的教师对本学科知 识有很深的研究; 有的教师擅长课题立项; 有的教师擅长学生管理研究等。 根据相对应的教师特点, 共同体为教师配备相应的师傅。

3. 2 教学资源共享

教师成长共同体建立教学互动工作群 (QQ群、微信群、钉钉群), 进行
动态、开放、互动的网络教研。

学校开发适用于教师网络培训的平台一一教研协作共同体视频点播 系统, 内容可为名师讲座、教学影像等; 建立协作体资源库中心, 包括网络 设备、资源库、教学软件 (课件、影像资料、APP等) ; 建立网上交流机制, 以教师困惑的、需要极力推行的教学方法、教学策略、教学理念为主题内 容, 全体教师通过平台交流实践的成功与困惑。

把学科协作研修、协作教学研究、协作课题研究逐渐迁移到教学互动 工作群上来。也可以把共同体中教师日常的生活感悟、教学心得、教案设 计、视频课堂实录、课件等发布到教学互动工作群上来, 它为教师教育思 想的产生、碰撞、升华、成熟与累积提供一个很好的平台。

\section{4 自我规划一一明确自我发展目标}

教师的成长离不开合理规划与自觉反思, 合理的专业成长规划有利于 教师做自己生命的设计师、领航员, 有利于教师过上幸福的教育生活, 实现 美好的人生。

教师成长共同体在制定《共同体发展三年规划》的基础上, 要求全体 成员结合自身特点制定专业成长发展三年规划, 认真思考三个问题: 我的 现状怎样? 我有怎样的发展目标? 我怎样实现发展目标 (具体有怎样的措 施策略)？

教师认真参与, 积极进行自我发展的设计规划并付诸实际行动实施。

\section{5 教学反思一一感悟提升教学实践}

教学反思, 是教师要对自己的教学活动、教学行为以及由此所产生的 过程与结果进行审视和分析, 是从感性认识到理性认识的过程, 是对教育 教学规律的探索与发现, 教学工作 “再创造” 的过程。按教学的进程, 教学 反思分为 “课前——课中一一课后” 三阶段进行反思, 反思每阶段的过程 结果与感悟体会, 教师在自我否定完善之中进一步提升发展。

区域名师成长共同体和校级教师成长共同体, 都应注重共同体成员撰 写教学反思。通过反思可以提高教师教学的自觉性和科学性; 可以培养教 师的观察能力, 思维能力; 可以使教师的思考由不成熟到成熟, 由成熟到理 性; 可以使教师扬长避短, 不断修正错误, 不断创新, 完善提升教学实践能 力, 同时自觉自主提升研究能力。

\section{6 结束语}

综上, 教师成长共同体, 通过导师专业引领、同伴互动共享、自我规划 反思, 教师在参与互动共享中提升课堂教学能力与教育研究能力, 提升个 体素养, 推进整体素养提升。教师成长共同体, 一群志同道合者一路同行, 一路互动分享, 共同提升。

\section{[参考文献]}

[1]杨忠君.试论以 “素养” 为内核的教师专业成长 [J]. 教育科 学,2015(04):46-50.

[2]全力. 名师工作环境中的教师专业成长 [J]. 当代教育科 学,2009(13):31-34.

[3] 蔡雅杰.构建教师学习共同体的策略 [J]. 新课程研究(下旬 刊),2017(7):12-13.

[4]张爱杰.教师学习共同体的构建障碍及对策研究[D].河南师范大 学,2016.

作者简介：

徐卫庆(1972--), 男, 汉族, 浙江杭州人, 大学, 中学高级教师, 研究方 向：教师职业素养提升。 